\title{
VECURONIUM INDUCED BRONCHOSPASM IN A PREGNANT PATIENT
}

\author{
Aparanji Koduri1 ${ }^{1}$ Padmaja Allu², K. Venkata Jaya Suman ${ }^{3}$
}

\section{HOW TO CITE THIS ARTICLE:}

Aparanji Koduri, Padmaja Allu, K. Venkata Jaya Suman. "Vecuronium Induced Bronchospasm in a Pregnant Patient". Journal of Evolution of Medical and Dental Sciences 2015; Vol. 4, Issue 16, February 23;

Page: 2823-2825, DOI: $10.14260 /$ jemds/2015/404

\begin{abstract}
Vecuronium, a commonly used neuromuscular blocking agent during general anaesthesia, induced bronchospasm in a pregnant patient posted for emergency caesarean section. Two episodes of bronchospasm shortly following administration of vecuronium. Vecuronium was the suspected culprit. Allergic skin tests proved that the bronchospasm is a manifestation of anaphylaxis induced by vecuronium.
\end{abstract}

KEYWORDS: Vecuronium, pregnancy, brochospasm, anaphylaxis.

INTRODUCTION: Isolated bronchospasm during general anaesthesia may be a single manifestation of serious underlying pathology such as anaphylaxis ${ }^{1}$. Untreated it can lead to hypoxia, hypotension and increased morbidity and mortality. In view of altered physiology in a pregnant woman, any episode of bronchospasm may severely affect both the foetal and maternal outcome. Neuromuscular blocking agents are most common agents leading to anaphylaxis perioperatively.

CASE REPORT: A 21 year old, $168 \mathrm{cms}$ tall, weight 60kgs, unbooked primigravida of 37 weeks gestational age in obstructed labour, with foetal distress was posted for emergency caesarean section. The patient was suffering from viral fever and her platelet count was 50,000 cells $/ \mathrm{mm}^{3}$. Bleeding time and clotting time were within normal limits. Patient had no history of bronchial asthma, no history of allergic reaction to medications or food and no family history of allergies.

In view of thrombocytopaenia, general anaesthesia was considered. Patient was given $30 \mathrm{ml}$ of $0.3 \mathrm{M}$ non-particulate sodium citrate solution preoperatively.

In the operating room, the patient was monitored with routine monitoring devices like NIBP, ECG, pulseoximeter. Vital signs were as follows SPO2 98\%, BP 110/80 and HR 86beats/minute.

Patient was premedicated with Injection Glycopyrrolate $0.2 \mathrm{mg} I V$, Injection ondansetron $4 \mathrm{mg}$ IV. Preoxygenated for five minutes with $100 \%$ oxygen. Patient was induced with injection Thiopentone sodium $250 \mathrm{mg}$ IV, Intubated with 7.0 size endotracheal tube after administration of injection succinylcholine $75 \mathrm{mg}$ IV. Sellicks manoeuvre was done throughout the procedure from induction to inflation of ET tube cuff.

Anaesthesia was maintained with 50\%02, 50\%N20 and Sevoflurane 1 MAC. Vecuronium 4mg IV was given after recovery from succinylcholine. Five minutes after Vecuronium administrstion, airway pressure was increased and SPO2 dropped to85\%.0n auscultation, extensive widespread wheeze was heard in bilateral lung fields.BP was 140/80 mmHg and HR 120/min. Immediately switched over to $100 \%$ oxygen ad ventilated manually. Anaesthesia was deepened with sevoflurane 2.0 MAC. After excluding ET tube for blocking and misplacement of tube, 8 puffs of salbutamol were given through metered dose inhaler. Injection Hydrocortione $200 \mathrm{mg}$ iv given. SPO2 gradually improved and airway pressures returned to normal and surgery was commenced. Twenty minutes after first dose of vecuronium, 1mg of vecuronium was given as maintenance dose, within one 


\section{CASE REPORT}

minute, again the airway pressures were increased and SPO2 dropped to $80 \%$ and bronchospasm was unresponsive to salbutomol puffs. Injection adrenaline 50micrograms iv given. SPO2 returned to $100 \%$ and airway pressures were returned to normal. Rest of the surgery was continued without neuromuscular blocking agent. Patient delivered live Female child with APGAR 6 and 8 at 1 and 5 minutes respectively. Rest of the intraoperative and postoperative period was uneventful.

Two episodes of bronchospasm shortly following vecuronium administration points out that vecuronium might be responsible. Mast cell tryptase test was not available to ascertain whether the brochospasm was a manifestation of anaphylactic reaction. So allergic skin test were planned and performed after two months. Skin tests were performed according to standardized procedures recommended by the commission tripartie on allergologie. ${ }^{2}$

Pick test was done with both positive and negative controls. Interpretation of test after 15 minutes revealed to be positive with the wheel diameter $60 \%$ that of positive control and $5 \mathrm{~mm}$ greater than that of negative control. Subsequently, intradermal test was done and test was proved to be positive at $10^{-4}$ dilution, and it confirmed that the bronchospasm was indeed a manifestation of anaphylaxis induced by vecuronium.

To ascertain the cross reactivity with other neuromuscular blocking agents, allergic skin tests to succinylcholine, rocuronium and atrcurium was conducted. Fortunately, none of them were proved to be allergic to this patient.

DISCUSSION: Anaphylaxis during anaesthesia carries major risk of morbidity and mortality. Clinical features may be myriad like cutaneous symptoms, angioedema, brochospasm, arterial hypotension, cardiovascular collapse and cardiac arrest. In a study conducted by Laxenaire et $\mathrm{al}^{3}$, bronchospasm constituted $44.2 \%$ of all, presenting symptoms due to anaphylaxis. Bronchospasm as a sole feature was observed among 15 patients.

Bronchospasm in a pregnant patient severely affect the survival chances of both the patriuritent and foetus owing to the altered physiological changes in pregnancy. Careful and aggressive management of bronchospasm may favour the positive outcome.

Most common agents responsible for perioperative hypersensitive reactions were neuromuscular blocking drugs followed by latex, antibiotics, opioids and colloids.

Neuromuscular blocking agents account for around 70\% of all perioperative hypersensitive reactions ${ }^{4}$ and aminosteroidal drugs outnumber the Benzylisoquinolones. ${ }^{5}$

Hypersensitive reactions to neuromuscular blocking agents may be due to nonspecific histamine release from mast cells [anaphylactoid reaction] or may be IgE mediated hypersensitive reactions [anaphylactic reaction]or may be due to high affinity to M2 muscarinic receptors leading to an augmented parasympathetic response to intubation causing severe bronchospasm mediated via M3 muscarinic receptors. ${ }^{6}$ Clinical symptoms and reaction severity do not allow one to distinguish between immune mediated anaphylactic reaction and anaphylactoid reaction resulting from direct nonspecific histamine release. Diagnosis of type I allergy mediated by specific IgE antibody is usually confirmed by skin tests.7,8,9

Allergic skin tests in this patient revealed the patient to be allergic to vecuronium and nonallergic to Succinyl choline, atracurium and Rocuronium and can be safely used in this patient. The bottom line is anaphylaxis may manifest in any form. Timely diagnosis and intervention prevents the morbidity and mortality. 


\section{REFERENCES:}

1. M. C.Laxenaire, PM Mertes and Group Etudes des Reactions Anaphylactoides peranesthesiques. Br J Anaesth 2001: 87: 549-58.

2. Laurent J. Commissium tripartie de consensus en allergologie. Rev Ev Allergol 1997; 37: 776-7.

3. Laxenaire MC Epidemiologie des reactions anaphylactoides per anesthesiques.

4. Peroni DG, San salter N, Bernardini R, Crisafull G, Franche Schini F, Caffarelli C, et al. Muscle relaxant allergy Int J immunopathol Pharmacol 2011; 24 [suppl3]; S3546.

5. Claudius C, Gravey L.H, Viby-Mogenseen et al. The undesirable effects of neuromuscular blocking drugs. J Anaesth 2009; 64[suppl] S10-21.

6. Jooste E,Klafter F, Hirshman CA, Emala CW. A mechanism for rapacuronium induced bronchospasm, M2muscuronic receptor antagonism. J Anesth 2003; 98: 906-11

7. Gallety DC, Treuren BC. Anaphylactoid reactions during anaesthesia, seven years of experience of intradermal testing. J Anaesth1985; 40: 329.33.

8. Fisher. M. Intradermal testing after anaphylactoid reaction to anaesthetic drugs, practical aspects of performance and interpretation. Anaesth Itensive care 1984; 12: 115-20.

9. Monoret-Vautrin D, laxenaire M. Skin tests in diagnosis of allergy to muscle relaxants and other anaesthetic drugs. Mangor Allergy 1992; 30: 145-55.

\section{AUTHORS: \\ 1. Aparanji Koduri \\ 2. Padmaja Allu \\ 3. K. Venkata Jaya Suman}

\section{PARTICULARS OF CONTRIBUTORS:}

1. Assistant Professor, Department of Anaesthesia, Andhra Medical College, Visakhapatnam.

2. Associate Professor, Department of Anaesthesia, Andhra Medical College, Visakhapatnam.

FINANCIAL OR OTHER

COMPETING INTERESTS: None
3. Post Graduate, Department of Anaesthesia, Andhra Medical College, Visakhapatnam.

\section{NAME ADDRESS EMAIL ID OF THE} CORRESPONDING AUTHOR:

Dr. Aparanji Koduri, \# 10_5_19, 21F,

Srinidhi Group House,

Kailasametta,

Visakhapatnam-530003.

E-mail: aparanjikoduri15@yahoo.in

Date of Submission: 01/02/2015.

Date of Peer Review: 02/02/2015.

Date of Acceptance: 13/02/2015.

Date of Publishing: 23/02/2015. 